\title{
EXPERIMENTAL EXPLORATION OF CUTTING FORCES DURING Milling OF MUlti-LA YeREd Metal MATERIALS
}

\author{
Franc Cus \& Uros Zuperl
}
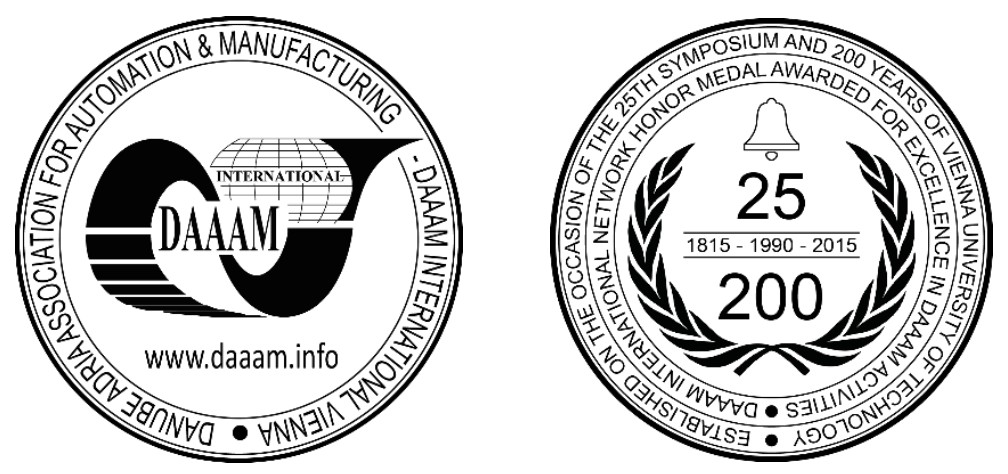

This Publication has to be referred as: Cus, F[ranc] \& Zuperl, U[ros] (2018). Experimental Exploration of Cutting Forces During Milling of Multi-Layered Metal Materials, Proceedings of the 29th DAAAM International Symposium, pp.0144-0148, B. Katalinic (Ed.), Published by DAAAM International, ISBN 978-3-902734-20-4, ISSN 1726-9679, Vienna, Austria

DOI: $10.2507 / 29$ th.daaam.proceedings.020

\begin{abstract}
In this research an experimental investigation of cutting forces during end-milling operation of four-layered metal material has been performed. The functionally graded metal material was manufactured by the laser engineered net shaping (LENS) process. Based on the experimental data the adaptive neural fuzzy inference system (ANFIS) was developed to predict the cutting forces while machining. Hardness and thickness of the particular manufactured layer in multi-layered metal material has been included in the cutting force analyses. ANFIS predictions were compared with experimental measurements and were found to be in good agreement. Experimental results demonstrate that ANFIS system can accurately predict cutting force within a maximum prediction error of $5.8 \%$. $\mathrm{Na}$
\end{abstract}

Keywords: end milling; cutting forces; multi-layered material; LENS; ANFIS

\section{Introduction}

Machining of functionally graded metal materials is an important manufacturing function in the automotive tool making industry. Due to the inhomogeneous structure of these modern metal materials manufactured with the LENS process, the machining of these materials leads to tool breakage, rapid cutting tool wear, surface deterioration and shelling of the layers. All of these effects are directly connected to the cutting tool forces. Therefore, there is a practical interest to analyse and precisely model the cutting forces during milling of these materials. Many parameters influence cutting forces in end-milling. Feedrate, cutting speed, cutting depth and tool geometry are controllable parameters, while tool wear, vibrations and workpiece/tool variability are uncontrollable. In manufacturing the relationship between process characteristics and cutting forces is difficult to capture. This is due to the complexity of the relationship between cutting forces and process characteristics. In workshops, inspection of cutting forces is accomplished by online measurements. This approach is uneconomical. Therefore, an in-process method based on prediction model is required. Several models have been proposed to estimate the cutting forces. These include classical statistical approaches as well as fuzzy systems and neural networks. 
Analytical cutting force modelling is difficult due to the large number of interrelated machining parameters. The researchers have been trying to develop mathematical models that would predict the cutting forces based on the geometry and physical characteristics of the process [1]. However, due to its complexity, the milling process still represents a challenge to the modeling and simulation research effort. In fact, most of the research work reported in this regard, which is based on either analytical or semi-empirical approaches, has in general shown only limited levels of accuracy and generality. For instance researchers [2] and [3] developed an approach based on the least-squares regression for estimating cutting forces in machining while [4] have, respectively, used genetic programming for estimating cutting forces over a limited range of cutting conditions.

The capacity of artificial neural networks to capture nonlinear relationships in a relatively efficient manner has motivated a number of researchers to pursue the use of these networks in developing cutting force prediction models [5]. Compared to traditional computing methods, the artificial neural networks (ANNs) are robust and global, but in such models, the nonlinear relationship between sensor readings and cutting forces embedded in a neural network remains hidden and inaccessible to the user [6].

In this research we attempt to solve this situation by using the ANFIS system to predict the cutting forces. This model offers ability to estimate cutting forces as its neural network based counterpart [7] but provides an additional level of transparency that neural networks fails to provide [8]. We try to investigate the possibility and effectiveness of predicting cutting forces with ANFIS method. It uses training examples as input and constructs the fuzzy if-then rules and the membership functions of the fuzzy sets involved in these rules as output.

Four milling parameters have been selected. After training the estimator, its performance was tested under various cutting conditions. Test data sets collected from a wide range of cutting conditions in end milling were applied to the estimator for evaluating the cutting forces. The obtained result for predicting cutting force has a highly correct rate.

\section{Predictive cutting force system}

The aim of this study is to develop an accurate and reliable model for predicting cutting forces during end milling process. This chapter outlines the adaptation of the ANFIS topology to the cutting force prediction problem. The cutting force prediction model is built according to the ANFIS method. The ANFIS method seeks to provide a linguistic model for the prediction of cutting forces from the knowledge embedded in the trained neural network.

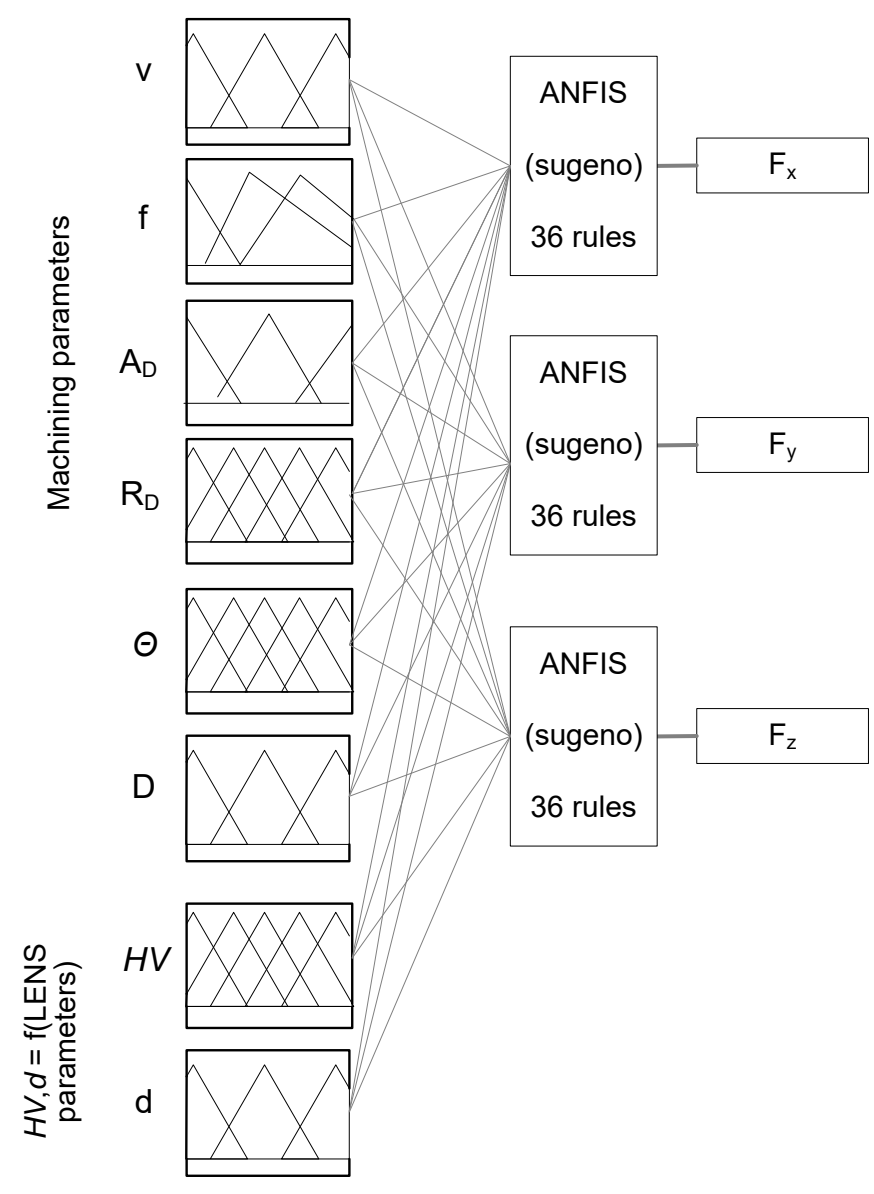

Fig. 1. Architecture of ANFIS cutting force model 
The training data set is used to find the initial premise parameters for the membership functions by equally spacing By given input/output data set, the ANFIS method constructs a fuzzy inference system (FIS) whose membership function parameters are tuned (adjusted) using a backpropagation algorithm. This allows fuzzy systems to learn from the data they are modeling. FIS Structure is a network-type structure similar to that of a neural network, which maps inputs through input membership functions and associated parameters, and then through output membership functions and associated parameters to outputs.

Four steps are required to develop an ANFIS system. In step 1, the training and testing data are loaded to the system. The process variables are spindle speed $n$, feed rate $f$, axial depth of cutting $A_{D}$, radial depth of cutting $R_{D}$, the angle of cutting tool rotation $\Theta$, cutting tool diameter $\mathrm{D}$, the hardness of the machined material $\mathrm{HV}$ and the thickness of manufactured layer $d$. The output from the ANFIS are three cutting force components. All the data were scaled. The whole data set is divided into the training and the testing set. 525 data points were used in this study.

each of the membership functions. A threshold value for the error between the actual and desired output is determined.

The FIS architecture and training parameters were defined in step 2. The optimization method, the tolerance error, the maximal number of epoch, the number of membership functions and the membership functions types are defined. The ANFIS architecture is explained in detail in [8]. In step 3, the training phase is accomplished. With the inputoutput data, the neuro-fuzzy algorithm is trained, and the unknown parameters are identified. Figure 1 shows the inputs, membership functions, and the fuzzy inference system for cutting force prediction. During the training stage, the ANFIS adjusts its internal structure to give correct output results according to the input features. The training process is terminated when the error becomes less than the threshold value.

During training in ANFIS, 400 sets of experimental data are used to conduct 500 cycles of learning. Training of the ANFIS can be stopped by two methods. In the first method, ANFIS will be stopped to learn only when the testing error is less than the tolerance limit. This tolerance limit would be defined at the beginning of the training. It is obvious that the performance of a ANFIS that is trained with lower tolerance is greater than ANFIS that is trained with higher tolerance limit. In this method the learning time will change with the architecture of the ANFIS. The second method to stop the learning is to put constraint on the number of learning iterations. In our study, the ANFIS architecture is stopped to learn after 400 training iterations. Finally, in the fourth step the trained ANFIS is used to predict cutting forces. After the training, the inference system could estimate cutting forces from selected cutting conditions in real time. The developed ANFIS model can guide system or operator in tool change decisions making.

\section{Experimental test and equipment}

To build the ANFIS model, experimental results were obtained according to the following procedure:

1. Nine four-layered metal workpieces with different layer thicknesses were produced.

2. Thickness $d$ and hardness HV of manufactured layers were measured.

3. A total of 243 machining tests were carried out to obtain cutting forces in three directions; 27 tests were conducted on each workpiece. Each test was repeated three times under the same operating parameters.

5. The results of measured cutting forces were analysed and prepared for ANFIS training.

The machining experiments were carried out on the CNC milling machine (type HELLER BEA02), under dry cutting conditions. The cutting forces in the feed Fx, normal Fy and axial directions Fz were measured with a Kistler (Type 9257) piezoelectric dynamometer. The signals were conditioned through a dual mode charge amplifier (Type 5001 ) with a low pass filter of $1 \mathrm{kHz}$ cut-off frequency. The used filter is a one pole passive filter with second order Butterworth characteristic. The low pass filter is set to about one-third of the natural frequency of the dynamometer. The analogue force signal is then output to an NI 925A board control by the Labview software.

The solid ball-end milling cutting tools (Tornado) of $8 \mathrm{~mm}$ diameter with two cutting edges, of $29.9^{\circ}$ helix angle and $2.28^{\circ}$ rake angle were used. The ball-end mills were made of a sintered tungsten carbide material K88UF with the hardness of $1770 \mathrm{HV}$. The cutting edges were coated with PVD-TiAlN coating. The machining tests were carried out for all combinations of machining parameters and LENS process parameters. One and/or three values for the radial and axial depth of cut have been selected: $R_{D 1}=0.2 \mathrm{~mm} ; A_{D 1}=0.5 \mathrm{~mm}, A_{D 2}=1 \mathrm{~mm}, A_{D 3}=1.5 \mathrm{~mm}$. The following values for spindle speed and feed rate have been selected: $\mathrm{n}_{1}=3000 \mathrm{~min}^{-1}, \mathrm{n}_{2}=3600 \mathrm{~min}^{-1}, \mathrm{n}_{3}=4000 \mathrm{~min}^{-1} ; \mathrm{f}_{1}=200 \mathrm{~mm} / \mathrm{min}$, $\mathrm{f}_{2}=250 \mathrm{~mm} / \mathrm{min}, \mathrm{f}_{3}=300 \mathrm{~mm} / \mathrm{min}$. The combination of three values for the Laser power $(\mathrm{P})$ and the cladding speed (c) was used to make the four-layered material: $\mathrm{P}_{1}=300 \mathrm{~W}, \mathrm{P}_{2}=380 \mathrm{~W}, \mathrm{P}_{3}=400 \mathrm{~W} ; \mathrm{c}_{1}=30 \mathrm{~mm} / \mathrm{s}, \mathrm{c}_{2}=48 \mathrm{~mm} / \mathrm{s}, \mathrm{c}_{3}=60$ $\mathrm{mm} / \mathrm{s}$. The workpiece material is made of a $16 \mathrm{MnCr} 5$ basic material and 4 stainless steel (316L) layers with a singular $0.3 \mathrm{~mm}$ to $1.0 \mathrm{~mm}$ thickness, length of $50 \mathrm{~mm}$ and width of $15 \mathrm{~mm}$.

Nine such belts of stainless steel layers were cladded on a singular workpiece with the $60 \mathrm{~mm}$ thickness, length of $180 \mathrm{~mm}$ and width of $70 \mathrm{~mm}$. By varying the two LENS process parameters, 9 different test workpieces ( 9 tests) of four-layered metal material with different layer hardness and thickness were produced on the Optomec LENS 850-R machine. The overlapping in all layers was set to $40 \%$. The diameter of laser ray was $0.8 \mathrm{~mm}$. The experimental setup can be seen in Fig. 2.The Vickers hardness of manufactured layers was measured by 7061 Zwick 3212 hardness tester. Layer thicknesses d of the manufactured metal material were measured with a Nikon Epiphot 300 Inverted Metallurgical Microscope. 


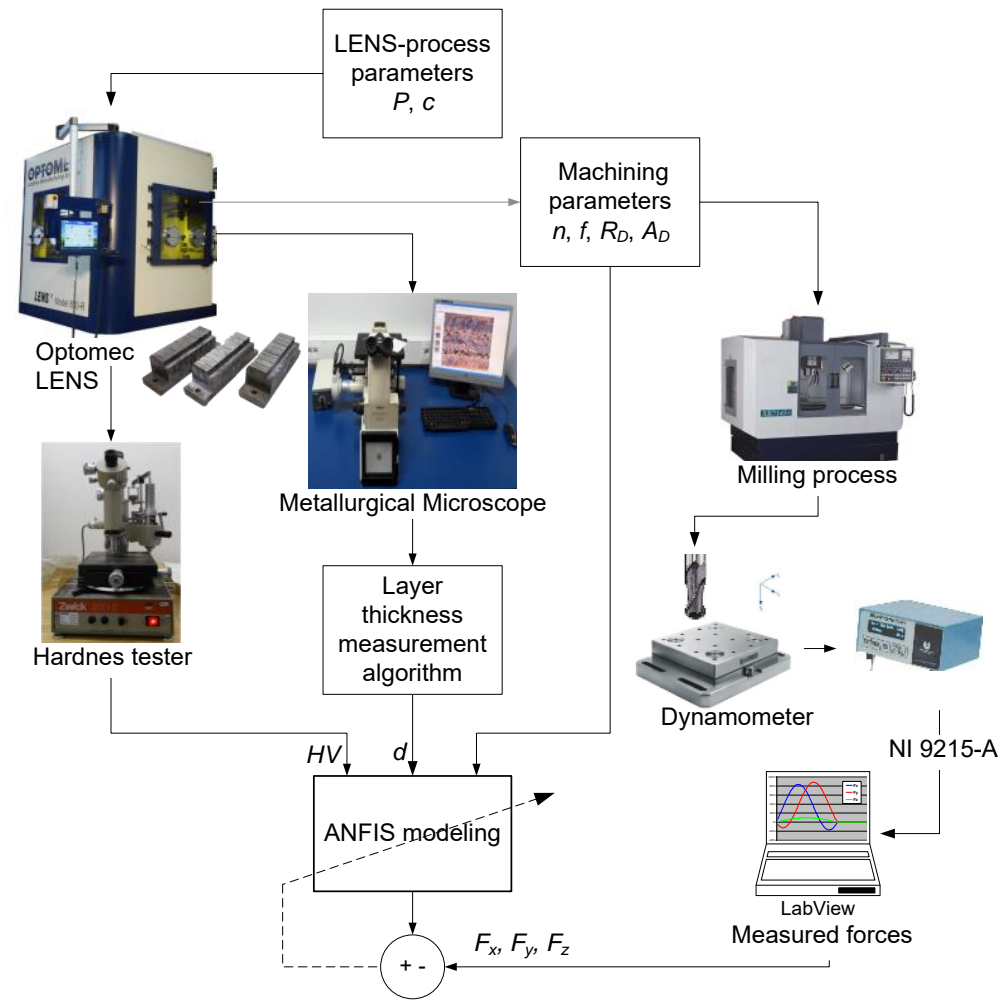

Fig. 2. Experimental equipment;

\section{Modelling and cutting force analyses results}

The prediction results and/or the values of measured cutting forces are graphically represented by means of diagrams depending on the angle of rotation of the cutting tool (Fig. 3). Samples of the cutting forces obtained during milling of the four-layered metal material are represented by a continuous line.
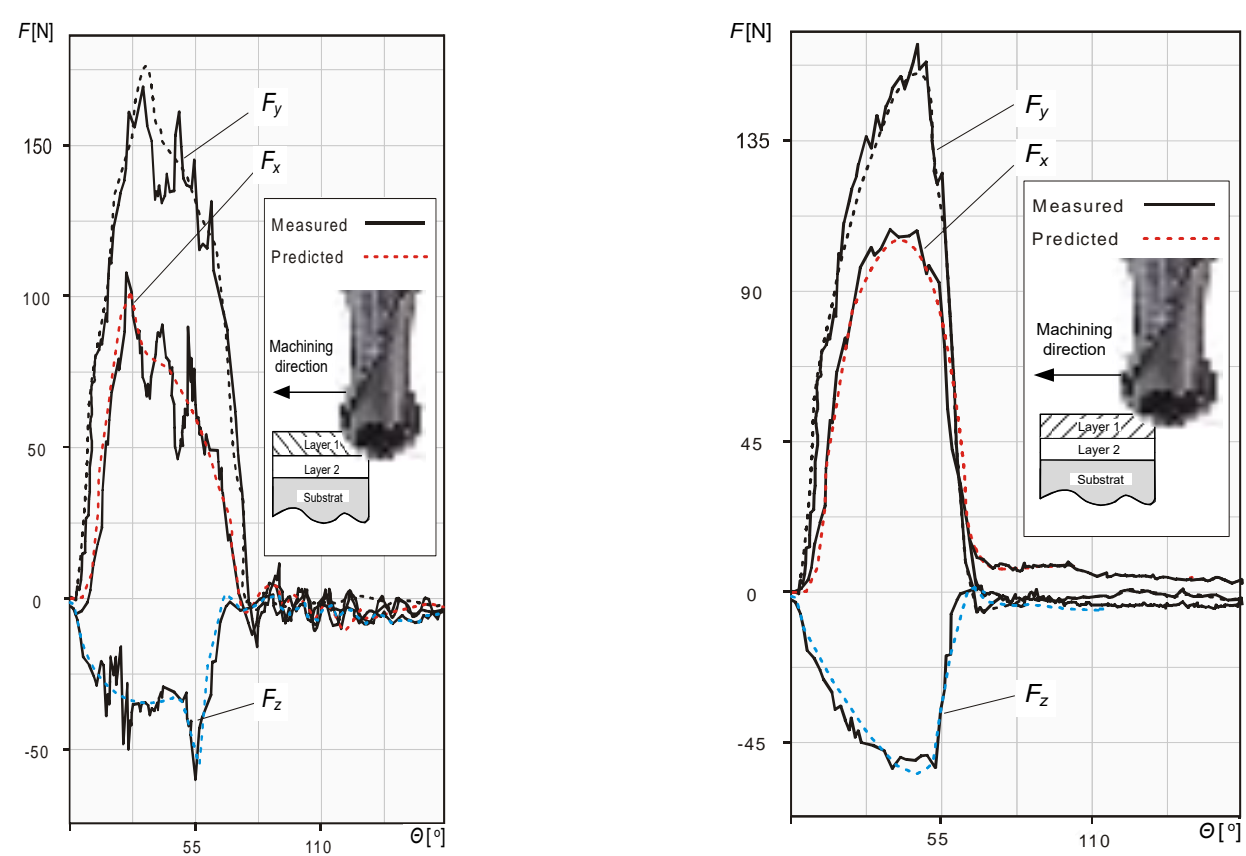

Fig. 3. Eexperimental and predicted forces for $16 \mathrm{MnCr} 5 / 316 \mathrm{~L}$ four-layered material at: a) middle depth of cutting $\mathrm{A}_{\mathrm{D}}$ $=0.45 \mathrm{~d} ; \mathrm{b}$ ) at high depth of cutting; $\mathrm{A}_{\mathrm{D}} \approx \mathrm{d}$;

The force signals outline the tool engagement in $1 / 2$ revolution. Each force signal was obtained by averaging ten one-revolution engagements at different time periods in the cutting test in order to eliminate signal anomalies due to the inhomogeneity of the manufactured stainless steel layers. 
The force signals clearly outline one characteristic peak corresponding to the engagement of the one flute, separated by periods of no engagement. The rise of the cutting forces in each cycle is due to the increase of chip thickness from zero at the cutting edge entry to a maximum at the exit. The force signal is also influenced by the direction of layer cladding. The order in which the peak forces appear and the spacing between them is also related to the number of manufactured layers and their thickness. The cutting forces for milling at the ratio $A_{D} / d=0.55$ are relatively higher than expected for milling when the $A_{D} \approx d$ (Fig. 3). Force signals also exhibit more fluctuation. This is probably due to the material inhomogeneity at the border between separate stainless steel layers. The chip obtained in this region is heavily discontinuous and very small. Force fluctuations and magnitude increase slightly as $A_{D}$ becomes larger than d. It was found that feed rate has the largest impact on cutting force. The cutting force decreases when the feed rate decreases. It is also obvious that the force signal for the multi-layered material is characteristic of the architecture of the material, which depends on the LENS machine settings. The analysis indicate that two-way (dual) effect interaction $\mathrm{P} \times \mathrm{c}$ has a significant effect on the value of the resultant cutting force F. The laser power setting has the second largest impact on the cutting force. Several experimental tests have been performed in order to validate the developed ANFIS model for different cutting conditions and LENS machine parameters. The maximum percentage prediction cutting force error is found to be less than $5.8 \%$ for all the cases tested.

\section{Conclusion}

The machining of multi-layered metal materials with theirs inhomogeneous structure leads to undesirable tool breakage, rapid cutting tool wear and surface deterioration. These undesirable effects are directly connected to the cutting tool forces which can be seen as a control parameter in milling of these materials. Knowing the cutting forces is fundamental for understanding the machining processes, optimizing the process and evaluating the presence of instabilities that could affect the effectiveness of milling. Therefore, there is a practical interest to analyse and predict precisely the cutting forces during milling of multi-layered metal materials.

This paper presents the experimental exploration of cutting forces produced during end milling of multi-layered metal materials manufactured by the laser engineered net shaping (LENS) process. The force analysis results are employed to develop an adaptive neural inference system (ANFIS) for predicting the cutting forces during the machining of $16 \mathrm{MnCr} 5 / 316 \mathrm{~L}$ four-layered metal material with a solid carbide ball-end mill. Model predictions were compared with experimental data and were found to be in good agreement. Experimental results demonstrate that this method can accurately predict cutting force within a maximum prediction error of 5.8\%. It was found that the layer thickness has a significant influence on predicted cutting forces and the cutting forces when milling at the border between separate stainless steel layers exhibit fluctuations and magnitude increase due to material inhomogeneity.

Future activities will be carried out to integrate the ANFIS model to tool shop and to upgrade it with different tool/workpiece combinations in real time during milling. In the future the ANFIS model will be integrated in the adaptive force control system in order to replace the unpractical and expensive dynamometer. An adaptive force control with the on-line cutting force prediction model will be capable of controlling the cutting forces in real time.

\section{References}

[1] Jahromi, A.S. \& Bahr, B. (2010). An analytical method for predicting cutting forces in orthogonal machining of unidirectional composites, Composites Science and Technology, Vol. 70, No. 16, 2290-2297, DOI:10.1016/j.compscitech.2010.09.005

[2] Kim, S. J. (2016). Integration of Pre-Simulation and Sensorless Monitoring for Smart Mould Machining, International Journal of Simulation Modelling, Vol. 15(4), 2016, pp. 623-636, 1726-4529, DOI:10.2507/IJSIMM15(4)4.354

[3] Omelchak, A.; Fecak, S.I. \& Idrisova, U.V. (2016). Dynamic Processes in a Machine-Tool at High-Speed Machining, Chapter 16 in DAAAM International Scientific Book 2016, pp.175-182, B. Katalinic (Ed.), Published by DAAAM International, ISBN 978-3-902734-09-9, ISSN 1726-9687, Vienna, Austria, DOI:10.2507/daaam.scibook.2016.16

[4] Zhou, H.M.; Deng, J.X. \& Xie, W.W. (2010). Milling force forecast of the matching of lengthened shrink-fit holder and cutter in high speed machining, Advanced Materials Research, Vol. 139-141, pp. 827-830, DOI:10.4028/www.scientific.net/AMR.139-141.827.

[5] Aykut, Ş.; Gölcü, M.; Semiz, S.; \& Ergür, H.S. (2007). Modeling of cutting forces as function of cutting parameters for face milling of satellite 6 using an artificial neural network, Journal of Materials Processing Technology, Vol. 190, No. 1-3, pp. 199-203, DOI:10.1016/j.jmatprotec.2007.02.045.

[6] Zuperl, U.; Cus, F. \& Reibenschuh, M. (2012). Modeling and adaptive force control of milling by using artificial techniques, Journal of Intelligent Manufacturing, Vol. 23, No. 5, pp. 1805-1815, DOI:10.1007/s10845010-0487-z.

[7] Sui, X.L.; Zhang, J.T.; Ge, J.H.\& Wang, Y. P. (2008). Modeling and simulation of milling force in virtual numerical control milling process. Key Engineering Materials, Vol. 392, pp. 697-702.

[8] Zetek, M.; Vozár, V.; Bakša, T., \& Zetková, I. (2017). Influence of the Milling Cutter Diameter on the Cutting Tool Life when Machining Inconel 718, Proceedings of the 28th DAAAM International Symposium, pp.04170422, B. Katalinic (Ed.), Published by DAAAM International, ISBN 978-3-902734-11-2, ISSN 1726-9679, Vienna, Austria, DOI: 10.2507/28th.daaam.proceedings.05 